\title{
HPLC ANALYSIS OF EXTRACTS OF FRESH PETALS OF PAPAVER RHOEAS L.
}

\author{
JASMINA M. VELICKOVIC ${ }^{a}$, MILAN N. MITIC ${ }^{b}$, BILJANA B. ARSIC ${ }^{b}$, \\ DUSAN Đ. PAUNOVIC ${ }^{a}$, BRANKA T. STOJANOVIC ${ }^{a}$, \\ JOVANA N. VELJKOVIC ${ }^{b}$, DANICA S. DIMITRIJEVIC ${ }^{a}$, \\ SLAVICA D. STEVANOVIC ${ }^{a}$, DANIJELA A. KOSTIC ${ }^{\text {b* }}$
}

\begin{abstract}
Papaver rhoeas L. (Papaveraceae) is an annual grass native to many regions of the world, which is known to possess several pharmacological activities. It is also known that represent a rich source of anthocyanins. In this study, the content of the anthocyanin was determined in the examined various extracts of fresh petals by HPLC analysis. The most represented anthocyanins in the extracts of Papaver rhoeas L. are delphinidin-3-O-glucoside, cyanidin-3-O-glucoside, cyanidin-3-O-rutinoside, peonidin-3-O-glucoside, petunidin-3-O-glucoside, petunidin-3-acetylglucoside, and delphinidin-3-p-coumaroylglucoside. Acyl derivatives of anthocyanins in the water extract have not been identified. By comparing the contents of individual anthocyanins, the glycosides (polar) are better extracted with $50 \%$ alcohol solution, and their acyl derivatives are better extracted with pure alcohol. The water solution is the least suitable for anthocyanin extraction.
\end{abstract}

Keywords: anthocyanins, Papaver rhoeas L., HPLC analysis.

\section{INTRODUCTION}

Medicinal plants and their extracts deserve special attention because of the vital influence they have on human health. For the majority of the world population, medicinal plants represent the primary source of health care. According to the World Health Organization (WHO) report, almost $80 \%$ of people in marginal communities use only medicinal plants for the treatment of various diseases [1].

\footnotetext{
a University of 'Union - Nikola Tesla' Beograd, Department of Advanced Food Technologies, Faculty of Applied Sciences, Dušana Popovića 22a, 18000 Niš, Republic of Serbia

b University of Niš, Faculty of Sciences and Mathematics, Višegradska 33, 18000 Niš, Republic of Serbia

*Corresponding author: danijelaaakostic@yahoo.com
} 
JASMINA VELICKOVIC, MILAN MITIC, BILJANA ARSIC, DUSAN PAUNOVIC, BRANKA STOJANOVIC, JOVANA VELJKOVIC, DANICA DIMITRIJEVIC, SLAVICA STEVANOVIC, DANIJELA KOSTIC

Papaver rhoeas L. (family: Papaveraceae) is commonly known as corn poppy and found wild in various parts of the world. Papaver rhoeas L. has a long history of medicinal usage. Extracts derived from this plant have been used for the treatment of a wide range of diseases including inflammation, diarrhea, sleep disorders, cough, analgesia and also the reduction of withdrawal signs of the opioid addiction [2,3]. The flowers of corn poppy have a long history of medicinal usage, especially for ailments in the elderly and children. However, the plant does contain alkaloids, which are still under investigation, and so should only be used under the supervision of a qualified herbalist. The flowers and petals are anodyne, emollient, expectorant, hypnotic, slightly narcotic, and sedative [4]. An infusion is taken internally in the treatment of bronchial problems and coughs, insomnia, poor digestion, nervous, digestive disorders, and minor painful conditions. The flowers are also used in the treatment of jaundice. The petals are harvested as the flowers opened and dried for later use. They should be collected on a dry day and can be dried or made into syrup. The plant has been suggested to have anticancer properties [5].

Anthocyanins which are natural pigments widely distributed in nature, responsible for the colors of innumerable fresh petals. The common anthocyanidins found in the majority of colored plants are pelargonidin, cyanidin, delphinidin, peonidin, petunidin, and malvidin. The proportion and amount of each anthocyanidin are significantly influenced by cultivar type and agricultural conditions [5].

The effects of concentration methods such as vacuum, microwave and conventional heating methods on total phenolic and anthocyanin contents, antiradical activity, antioxidant capacity and color of Papaver rhoeas L. (poppy) sorbet, a traditional beverage of Turkey, were investigated. The lowest initial anthocyanin content was found to be $571.31 \mathrm{mg}$ cyn-3-glu/kg using the conventional method, and the highest anthocyanin content was determined to be $774.49 \mathrm{mg}$ cyn-3-glu/kg in the vacuum treated sorbet at the beginning of the storage. Their results revealed that the poppy sorbet was an excellent source of phenolics and anthocyanins. Storage degradation of poppy anthocyanins followed the first-order reaction kinetics. The concentration method and storage temperature had a significant effect on the bioactivity and color of sorbets [6].

The variation in anthocyanins content of the petals of red poppy (Papaver rhoeas L.) during the development of the flower from the closed bud stage has been investigated by thin-layer chromatography. The densitograms were recorded at $465 \mathrm{~nm}$; they show gradually increasing peaks of red anthocyanins in the petals of closed buds, partly opened buds and fully developed flower and changes in the proportions of several anthocyanins, with various $R_{F}$ values, during the growth of the flower [7]. 
In our previous work, the contents of total phenols, flavonoids, anthocyanins in different extracts of petals of $P$. rhoeas $L$. were determined, and it was found to contain high concentrations of these compounds. Their antioxidant activity was also tested using the DPPH method, and it was found to exhibit high antioxidant activity. The examined extracts show both antibacterial and antifungal activity [8]. $P$. rhoeas $L$. was the subject of the investigation earlier [9], but our previous study is complementary to the investigations by other research groups.

Anti-oxidant and anti-radical in vitro properties and in vivo topical antiinflammatory activity of ten hydroalcoholic extracts of edible plants including poppy (Papaver rhoeas L. ssp.), from the Calabria region (Italy) were reported as well [10].

Antioxidant, antimutagenic and anticarcinogenic properties of $P$. rhoeas L. extract have been studied recently on Saccharomyces cerevisiae. Based on the well-expressed properties obtained in this work, the $P$. rhoeas L. extract could be recommended for further investigations and possible use as a food additive [11].

Qualitative and quantitative determinations of the contents of flavonoids and anthocyanins in various extracts obtained from $P$. rhoeas $L$. using the HPLC method was not performed before, so we are the first research group who has investigated, and reported the results. The influence of solvent on the extraction of these compounds was investigated in order to find the best solvent for the extraction which can be used in food industry.

\section{RESULTS AND DISCUSSION}

Red pigment, a natural antioxidant present in the petals of the red poppy, belongs to anthocyanins. Anthocyanin is the general name applied to the glycosides of anthocyanidin chromophores which are the origin of the red, violet, and blue colors found throughout the plant kingdom, such as the colors of petals, leaves, and fruits. Only a few anthocyanidin nuclei have been found despite the great variety of plant colors. The major anthocyanidins found in nature are pelargonidin, cyanidin, peonidin, delphinidin. The content of anthocyanins in our previous work ranged from $4.72-5.193 \mathrm{mg} / \mathrm{g}$ of fresh petals in different extracts of $P$. rhoeas $L$. from South-east Serbia [8].

The content of total anthocyanins determined by the $\mathrm{pH}$ differential method does not provide a complete picture of the quantity and quality of anthocyanins in the extracts of the investigated plant species due to the possible presence of interfering compounds. 
Using HPLC-DAD techniques, a comparative analysis of the quantities of anthocyanins in investigated extracts was performed. The phenolic components present in samples were identified by the comparison of the retention times and spectra of the standards for each component. Quantitative determination was performed by the method of the external standard. The following standards were used: delphinidin-3-O-glucoside, cyanidin-3-Oglucoside, cyanidin-3-O-rutinoside, peonidin-3-O-glucoside, petunidin-3-Oglucoside, petunidin-3-O-glucoside acylated, delphinidin-3-O-glucoside- $p$ coumaroyl, chlorogenic acid, caffeic acid, quercetin, myricetin. For each standard, the first standard was prepared with the mass concentration $1.0 \mathrm{mg} / \mathrm{ml}$, by dilution in $10 \%$ methanol solution. The calibration curve was constructed on the basis of the obtained areas depending on the mass concentration of the standard. From the obtained equation of linear dependence, the mass concentrations of components were calculated in the samples. For the components without available standards, the quantification was performed on the basis of the calibration curve according to the structure of the corresponding standard. All analyses were performed in triplicates.

Figure 1 shows a chromatogram of $50 \%$ ethanol extract of petals of $P$. rhoeas $\mathrm{L}$.

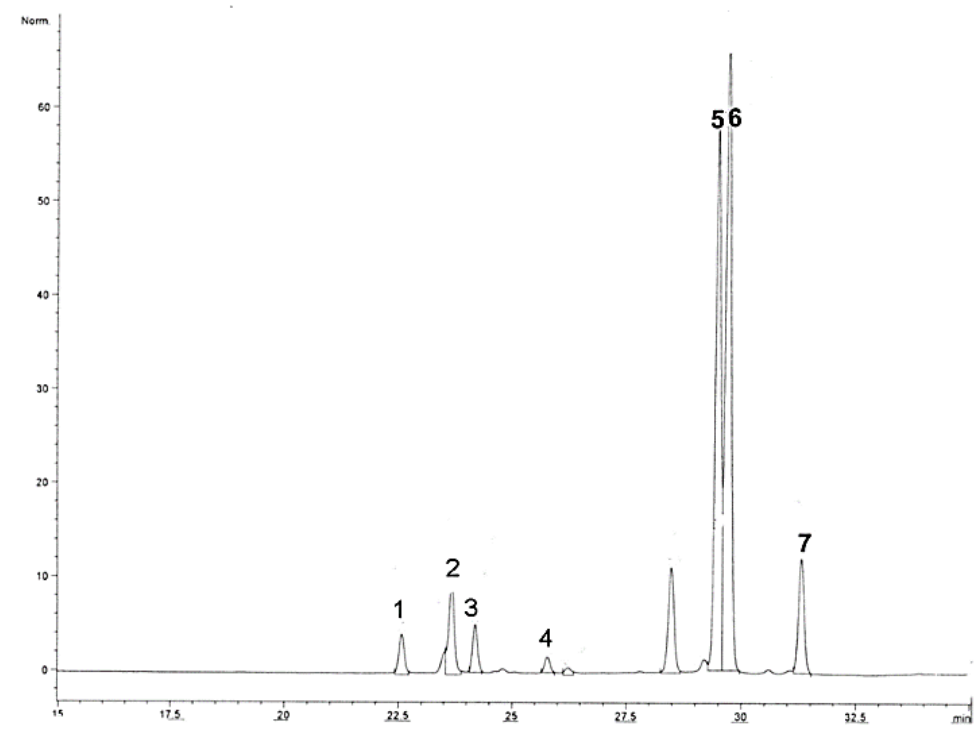

Figure 1. Anthocyanins content in the ethanol $50 \%$ extracts of fresh petals (Papaver rhoeas L.): delphinidin-3-O-glucoside (1), cyanidin-3-O-glucoside (2), cyanidin-3-O-rutinoside (3), peonidin-3-O-glucoside (4), petunidin-3-O-glucoside (5), petunidin-3-O-acetylglucoside (6), delphinidin-3-O-p-coumaroylglucoside (7). 
Seven phenolic compounds were identified as anthocyanins due to the information provided by their UV-Vis spectra. Thus, five glucosylated anthocyanins ( $\lambda_{\max }=520 \mathrm{~nm}$ ) were identified: delphinidin-3-O-glucoside, cyanidin3-O-glucoside, cyanidin-3-O-rutinoside, petunidin-3-O-glucoside, peonidin-3-Oglucoside, and acylglucosylated anthocyanins: petunidin-3-O-acetylglucoside and delphinidin-3-O-p-coumaroylglucoside. Structures of identified anthocyanins in extracts of fresh petals of $P$. rhoeas $\mathrm{L}$. are shown in Table 1.

Table 1. Structure of identified anthocyanins in extracts of fresh petal of $P$. rhoeas $\mathrm{L}$.

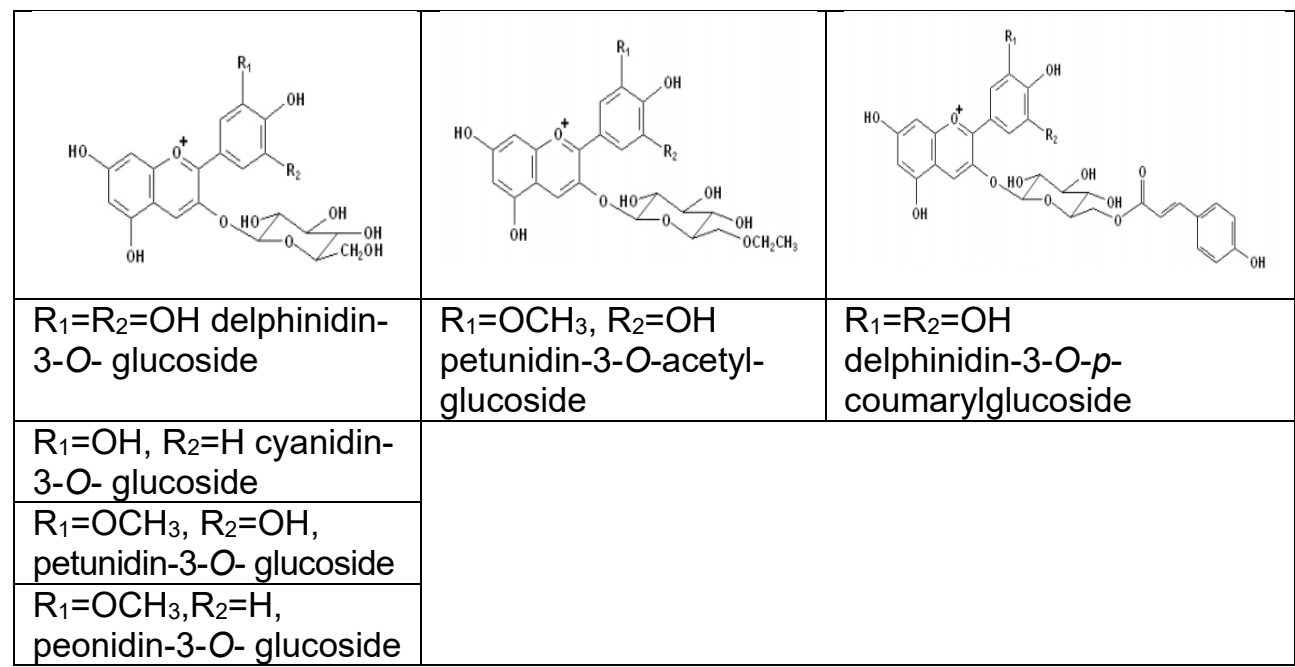

The content of anthocyanins in different extracts of fresh petals of $P$. rhoeas L. was shown in Table 2 .

In investigated extracts of fresh petals of $P$. rhoeas L. plants, glucosides of four anthocyanins were identified: delphinidin, cyanidin, petunidin, peonidin and acyl derivatives of petunidin (petunidin-3-O-acetylglucoside) and malvidin (delphinidin-3-O-p-coumarylglucoside).

Order of anthocyanins by content in methanol extracts and methanol $50 \%$ :

Methanol: Ptgl $<$ Dpgl<Cyrut $<$ Cygl $<$ Dpgl-coum $<$ Pngl $<$ Ptgl-ac

Methanol 50\%: Ptgl $<$ Dpg $\mid<$ Cyrut $<$ Cyg $<$ Dpgl-coum $<$ Pngl $<$ Ptgl-ac

The content of polar anthocyanins is larger in extracts of $50 \%$ methanol, and less polar anthocyanins in pure methanol.

Order of anthocyanins by content in ethanol extracts and ethanol $50 \%$ :

Ethanol: Ptgl-ac $<$ Pngl $<$ Dpgl-coum $<$ Cyg $\mid<$ Cyrut $<$ Dpg $\mid<$ Ptgl

Ethanol 50\%: Ptgl-ac<Pngl $<$ Dpgl-coum $<$ Cygl $<$ Cyrut $<$ Dpgl $<$ Ptgl 
JASMINA VELICKOVIC, MILAN MITIC, BILJANA ARSIC, DUSAN PAUNOVIC, BRANKA STOJANOVIC, JOVANA VELJKOVIC, DANICA DIMITRIJEVIC, SLAVICA STEVANOVIC, DANIJELA KOSTIC

Table 2. Content of anthocyanins in the different extracts of fresh petals of Papaver rhoeas L.

\begin{tabular}{|c|l|c|c|c|c|c|}
\hline & Anthocyanins & $\begin{array}{c}\text { Methanol } \\
\mathrm{mg} \mathrm{L}^{-1}\end{array}$ & $\begin{array}{c}\text { Methanol } \\
50 \% \mathrm{mg} \mathrm{L}^{-1}\end{array}$ & $\begin{array}{c}\text { Ethanol } \\
\mathrm{mg} \mathrm{L}^{-1}\end{array}$ & $\begin{array}{c}\text { Ethanol } \\
50 \% \mathrm{mg} \mathrm{L}^{-1}\end{array}$ & $\begin{array}{c}\text { Water } \\
\mathrm{mg} \mathrm{L}^{-1}\end{array}$ \\
\hline 1 & $\begin{array}{l}\text { Delphinidin-3-O- } \\
\text { glucoside (Dpgl) }\end{array}$ & $1.96 \pm 0.02$ & $2.02 \pm 0.02$ & $1.39 \pm 0.07$ & $1.44 \pm 0.03$ & $1.20 \pm 0.02$ \\
\hline 2 & $\begin{array}{l}\text { Cyanidin-3-O- } \\
\text { glucoside (Cygl) }\end{array}$ & $4.45 \pm 0.4$ & $4.64 \pm 0.04$ & $3.33 \pm 0.05$ & $3.60 \pm 0.04$ & $0.57 \pm 0.02$ \\
\hline 3 & $\begin{array}{l}\text { Cyanidin-3-O- } \\
\text { rutinoside (Cyrut) }\end{array}$ & $2.46 \pm 0.03$ & $3.30 \pm 0.15$ & $2.58 \pm 0.06$ & $2.62 \pm 0.01$ & $0.34 \pm 0.02$ \\
\hline 4 & $\begin{array}{l}\text { Petunidin-3-O- } \\
\text { glucoside (Ptgl) }\end{array}$ & $0.75 \pm 0.05$ & $0.95 \pm 0.02$ & $0.72 \pm 0.02$ & $0.85 \pm 0.02$ & $0.56 \pm 0.05$ \\
\hline 5 & $\begin{array}{l}\text { Peonidin-3-O- } \\
\text { glucoside (Pngl) }\end{array}$ & $20.50 \pm 0.35$ & $18.4 \pm 0.40$ & $14.89 \pm 0.32$ & $33.26 \pm 0.09$ & $0.68 \pm 0.03$ \\
\hline 6 & $\begin{array}{l}\text { Petunidin-3-O- } \\
\text { acetylglucoside } \\
\text { (Ptgl-ac) }\end{array}$ & $27.80 \pm 0.65$ & $19.42 \pm 0.30$ & $18.20 \pm 0.40$ & $15.29 \pm 0.70$ & \\
\hline 7 & $\begin{array}{l}\text { Delphinidin-3-O- } \\
\text { p-coumaroyl } \\
\text { glucoside } \\
\text { (Dpgl-coum) }\end{array}$ & $5.56 \pm 0.06$ & $4.194 \pm 0.02$ & $3.65 \pm 0.20$ & $3.22 \pm 0.3$ & - \\
\hline
\end{tabular}

The content of polar anthocyanins is higher in ethanol of $50 \%$, and the content of less polar anthocyanins is more abundant in pure ethanol.

The smallest content of the anthocyanin is in the water extract of fresh petals. The acyl derivatives are the least polar and not identified in the aqueous extract.

The differences in anthocyanins content depend on the used extraction medium as a consequence of different polarity of used organic solvents and their mixtures [12]. The content of anthocyanins represents the pharmacological characteristic of the plant. Based on numerous studies, it is known that the content of anthocyanins depends on genotype, soil conditions, and the difference in plant ripening [13-15]. Also, outdoor conditions, like altitude, light, temperature, the content of feeding material in the soil might affect phenylpropanoid metabolism [16]. 


\section{CONCLUSION}

The results revealed that the different extracts of fresh petals of Papaver rhoeas $\mathrm{L}$. were an excellent source of anthocyanins. The differences in anthocyanins content depend on the used extraction medium as a consequence of different polarity of used organic solvents and their mixtures. The retention times of anthocyanins on the chromatogram are following their polarity; glycosides initially occur, and their acyl derivatives at the end. The highest content of anthocyanins glucosides was determined in methanol and methanol $50 \%$ solution, and the smallest in aqueous solution. By comparing the contents of individual anthocyanins, the glycosides (polar) are better extracted with $50 \%$ alcohol solution and their acyl derivatives are better extracted with pure alcohol. The water solution is the least suitable for anthocyanin extraction.

This investigation is significant because the anthocyanins and their derivatives are vital herbal pigments and have a significant contribution to the antioxidant, antimicrobial, and other positive effects shown by extracts of $P$. rhoeas L.

\section{EXPERIMENTAL}

\section{Preparation of materials}

Fresh petals samples of Papaver rhoeas L. collected throughout May 2018, were used for the investigation. This region of Serbia (Soko Banja) at the foothills of the Rtanj Mountain is said to be free of harmful environmental influences, as it is mostly devoid of industries and major highways. A voucher specimen 13636 was deposited in the herbarium of the Faculty of Sciences and Mathematics, University of Nis. The plant species were identified by Marija Markovic, Department of Biology, University of Nis.

\section{Preparation of herbal extracts}

Fresh petals samples of Papaver rhoeas L. were grounded in a blender, and $2 \mathrm{~g}$ was extracted by the following solvents: ethanol and ethanol $50 \%$, methanol, and methanol $50 \%$ and water.

Extraction was carried out in an ultrasonic bath for 15 min three times in succession with $30 \mathrm{ml}$ of the solvent, respectively. The extract was filtered through a Buchner funnel and filter paper (blue-collar) (CHMLAB, Spain), transferred into a $100 \mathrm{ml}$ flask and made up to mark with the same solvent. 
JASMINA VELICKOVIC, MILAN MITIC, BILJANA ARSIC, DUSAN PAUNOVIC, BRANKA STOJANOVIC, JOVANA VELJKOVIC, DANICA DIMITRIJEVIC, SLAVICA STEVANOVIC, DANIJELA KOSTIC

\section{High-performance liquid chromatography (HPLC) analysis}

The fruit extracts were analyzed by the direct injection of the extracts, previously filtered through a $0.45 \mu \mathrm{m}$ pore size membrane filter, into the Agilent Technologies 1200 chromatographic system equipped with the Agilent photodiode array detector (DAD) 1200 with RFID tracking technology for flow cells and a UV lamp, an automatic injector, and Chemstation software. The column was thermostated at $30^{\circ} \mathrm{C}$. After injecting $5 \mu \mathrm{L}$ of the sample extract, the separation was performed in an Agilent-Eclipse XDB C-18 $4.6 \mathrm{~mm} \times 150$ $\mathrm{mm}$ column. Two solvents were used for the gradient elution: $\mathrm{A}-\left(\mathrm{H}_{2} \mathrm{O}+5 \%\right.$ $\mathrm{HCOOH})$ and $\mathrm{B}-\left(80 \% \mathrm{ACN}+5 \% \mathrm{HCOOH}+\mathrm{H}_{2} \mathrm{O}\right)$. The used elution program was as follows: from 0 to $28 \mathrm{~min}, 0.0 \% \mathrm{~B}$, from 28 to $35 \mathrm{~min}, 25 \% \mathrm{~B}$, from 35 to $40 \mathrm{~min}, 50 \% \mathrm{~B}$, from 40 to $45 \mathrm{~min}, 80 \% \mathrm{~B}$, and finally for the last $10 \mathrm{~min}$ again $0 \% \mathrm{~B}$. The detection wavelengths were 320 and $520 \mathrm{~nm}$. The identification and quantification of individual compounds were performed using calibration curves obtained with standard solutions of pure anthocyanins. The results are expressed as $\mathrm{mg} \mathrm{L}^{-1}$ of plant extracts.

\section{Statistical analysis}

The experimental results were expressed as mean value \pm standard error of the mean value of three replicates. In order to estimate statistically any significant differences among mean values, where applicable, the data were subjected to a one-way analysis of variance (ANOVA test) [17].

\section{REFERENCES}

1. WHO. WHO Guidelines on Safety Monitoring of Herbal Medicines in Pharmacovigilance Systems. Geneva, Switzerland: World Health Organization 2004.

2. A. Zargari, Medicinal Plants. 6th ed. Tehran University Press; 1995, pp. 145-150.

3. A. Zargari, Medical Plants, Tehran University, Tehran, 1994, vol. 1, pp. 91-102.

4. R. Soulimani, C. Younos, S. Jarmouni-Idrissi, D. Bousta, F. Khalouki, A. Laila, J. Ethnopharmacol., 2001, 74, 265-274.

5. A. Castañeda-Ovando, M. Pacheco-Hernández, M.E. Páez-Hernández, J.A. Rodríguez, C.A. Galán-Vida, Food Chem., 2009, 13, 859-871.

6. L. Ekici, LWT-Food Sci.Technol., 2014, 56, 40-48.

7. G. Matysik, M. Benesz, Chromatographia, 1991, 32 (1-2), 19-22. 
8. D.A. Kostić, S.S. Mitić, M.N. Mitić, A.R. Zarubica, J.M. Veličković, A.S. Dordević, S.S. Randelović, J. Med. Plants Res., 2010, 4, 1727-1732.

9. J.P. Rey, J. Levesque, J.L. Pousset, F. Roblot, J. Chromatogr. A, 1992, 596 (2), 276-280.

10. T. Todorova, M. Pesheva, F. Gregan, S. Chankova, J. Med. Food, 2015, 18, 460467.

11. F. Conforti, S. Sosa, M. Marrelli, F. Menichini, G.A. Statti, D. Uzunov, A. Tubaro, F. Menichini, Food Chem., 2009, 112, 587 - 594.

12. H. Eng Khoo, A. Azlan, S. Teng Tang, S. Meng Lim, Food Nutr. Res., 2017, 61(1), 1361779, DOI:10.1080/16546628.

13. D.D. Orhan, A. Hartevioğlu, E. Küpeli, E. Yesilada, J. Ethnopharmacol., 2007, 112(2), 394-400.

14. N. Gougoulias, N. Mashev, Oxid. Commun., 2015, 38(1), 25-34.

15. N. Gougoulias, Oxid. Commun., 2015, 38(1), 35-45.

16. R.A. Dixon, N.L. Paiva, Plant Cell, 1995, 7(7), 1085-1097.

17. Statistical Analysis and Reporting System, ser Guide, Version 1.0, IBM 1999. 